\title{
AUTOCONHECIMENTO, INTROSPECÇÃO E MEMÓRIA
}

\author{
António Marques*
}

\begin{abstract}
O texto se volta para o lugar operativo da memória no autoconhecimento. Servindo-se de referências clássicas, em particular as oriundas do confronto entre empirismo e racionalismo, pretende-se mostrar que o conhecimento do si mesmo, o qual é apenas adquirível por introspecção, é relativamente pobre. Contrapondo-se a estruturas duais de apresentação do problema, sugere-se, no texto, que a clarificação daquilo que pode ser considerado autoconhecimento e introspecção requer a consideração do papel que é desempenhado pela memória e pela avaliação da natureza epistêmica das retrodicções (ou seja, das declarações acerca de eventos passados, neste caso, acerca de eventos mentais passados). Como uma conclusão não definitiva, distinguindo autoconhecimento de autoconhecimento por introspecção, defende-se que o autoconhecimento por introspecção possui pelo menos três características: ter uma estrutura temporal dual baseada na memória, ser direto e possuir autoridade da primeira pessoa.

PALAVRAS-CHAVE: Autoconhecimento. Memória. Ceticismo. Introspecção.
\end{abstract}

"Eu queria dizer..." - Recordas-te de diversos pormenores. Mas mesmo conjuntamente não revelam esta intenção. É como se uma cena tivesse sido fotografada, só ficando visíveis alguns pormenores dispersos: aqui uma mão, ali um traço de um rosto, um chapéu - o resto é escuro. E agora é como se eu soubesse, com toda a certeza, o que é que a fotografia representa. Como se eu fosse capaz de ler o escuro (Wittgenstein, Investigações Filosóficas, p. 635).

O autoconhecimento (AC) possui uma variedade de dimensões, e os filósofos propuseram e continuam a propor uma multiplicidade de métodos para explorar ou estabelecer os princípios dessa particular forma de conhecimento, reconhecida como tal, nessa sua especificidade. O que é bastante impressivo na literatura filosófica - quer ela seja de inspiração analítica, quer se inclua no que geralmente se designa de filosofia continental - é o fato de que a relação usual entre AC, introspecção e reflexão não deixa espaço para o papel essencial da

* Doutor em Filosofia. Professor e Diretor do Instituto de Filosofia da Linguagem. Faculdade de Ciências Sociais e Humanas da Universidade Nova de Lisboa.

Avenida de Berna, 26-C. Cep: 1069-061. Lisboa - Portugal. marquesantoni@gmail.com memória. Assim, é sobre o lugar operativo da memória no AC que tratam as linhas que se seguem.

Tradicionalmente, as perspectivas empirista e racionalista dominaram a concepção epistêmica do AC. A primeira começa com Descartes, ou mesmo antes, e continua até Kant; a segunda inclui Locke e Hume como seus representantes mais proeminentes. Porém esse é um esquema demasiado simples e até errôneo, tendo em conta as posições diferentes e frequentemente contraditórias que existem, mesmo no interior de cada campo. É suficiente sublinhar que Descartes (ou o que pode ser designado como cartesianismo), o qual é apontado como o paradigma clássico do AC, assente na introspecção, assim como o conceito de reflexão que nele opera, é submetido a uma devastadora crítica na Crítica da Razão Pura de Kant, em particular no capítulo acerca dos "Paralogismos da Razão Pura". O fato é que é em Locke que se encontra um conceito claro de reflexão como uma peça essencial de introspecção e de autoconhecimento. A seguinte citação do Essay Concerning Human Understanding ilustra um conceito relativamente comum de reflexão que prevalece na literatura sobre esses tópicos: 
A mente, ao receber do exterior as ideias mencionadas nos capítulos anteriores, ao virar-se para o interior de si mesmo e ao observar as suas próprias ações acerca dessas ideias que possui, retira daí outras ideias, as quais são tão capazes de serem objetos da sua contemplação como quaisquer outros que ela recebe de coisas estranhas a si (Ensaio [...] II, cap.VI, tradução nossa do original inglês).

Objetos da "sua contemplação como quaisquer outros que ela recebe de coisas estranhas a si” são precisamente o que parece ser o núcleo de qualquer movimento introspectivo, mas é também o que o torna tão problemático.

Explorando ainda um pouco as posições empirista e racionalista, representadas por Hume e Kant, respectivamente, é notável que, no limite, elas podem conduzir ao cepticismo acerca do poder de a mente conhecer a si mesma, ou seja, da possibilidade de um genuíno AC. De fato, se pensarmos em Hume e em Kant como os mais proeminentes e os pontos culminantes de ambas as tradições relativamente ao AC, pareceria completamente aceitável sugerir que a introspecção desempenha sempre um papel metodológico determinante. No primeiro caso, lembremo-nos da famosa passagem do A Treatise of Human Nature relativamente à sua própria mente e aquilo que ele aí encontra: "Pela minha parte, quando entro mais intimamente naquilo a que chamo eu mesmo (myself), sempre tropeço em qualquer percepção particular e nunca observo nada mais senão percepção” (Hume, 1984, p. 300). No caso de Kant, na seção “Os Paralogismos da Razão”, porque ele está preocupado com a desconstrução de toda a metafísica dogmática acerca do "eu”, o instrumento introspectivo tambémé usado nos seguintes termos

Ora, na intuição interna nada existe de permanente, porque o 'eu' é meramente a consciência do meu pensamento. Assim, na medida em que não alcançamos para além do mero pensamento, ficamos sem a necessária condição para aplicar o conceito de substância, isto é, de um sujeito autosubsistente, o eu mesmo como ser pensante. $\mathrm{E}$, sem a realidade objetiva do conceito de substância, o conceito associado de simplicidade desaparece..." (Kant, .... B, 413, tradução nossa do texto alemão).
Com essas referências à tradição clássica e, em particular, a esses dois autores, desejo apenas mostrar que o conhecimento do si mesmo, o qual é apenas adquirível por introspecção, é relativamente pobre: um tipo de percepção, no caso de Hume, e a mera consciência do “eu”, no caso de Kant. Também, com essas observações, sugiro que o cepticismo acerca da possibilidade de um genuíno AC possui já, em minha opinião, as suas raízes na filosofia clássica, seja ela empirista, seja racionalista. Quando me refiro, no presente contexto, ao cepticismo relativamente ao conhecimento da nossa própria mente (ou de si mesmo), pretendo significar a nossa capacidade de conhecê-la através do dispositivo de uma estrutura dual, isto é, uma mente que olha para si mesma: uma mente que se coloca a si mesma como alvo. Surpreendentemente, se tomarmos os exemplos de ambos, Hume e Kant (por razões diferentes), esse alvo oferece-nos pouca coisa: a percepção de sentimentos ou de um "eu”, respectivamente. ${ }^{1}$

No entanto, a fim de circunscrever a noção de AC, torna-se necessário esclarecer, tão claramente quanto possível, a ligação entre reflexão e memória, e o meu argumento se assenta na concepção de que a estrutura dual de reflexão tem de ser revista através da introdução do papel da memória. Em consequência, sugiro que a clarificação daquilo que pode ser considerado AC e introspecção requer a consideração do papel que é desempenhado pela memória e pela avaliação da natureza epistêmica das retrodicções (ou seja, das declarações acerca de eventos passados, nesse caso, acerca de eventos mentais passados). Por isso, o meu argumento sustenta-se em diferentes tópicos a explorar e poderá ser desenhado da seguinte forma:

\footnotetext{
Na mesma linha, Wittgenstein (IF 413), citando William James, dá-nos uma interessante (e intencionalmente simplificada) imagem de operações introspectivas: "Aqui temos um caso de introspecção, não diferente da que deu a William James a ideia de que o 'si mesmo' consistia, sobretudo, em 'movimentos peculiares na baça e entre e cabeça e a garganta'. E, para James, 'a introspecção mostrou não o sentido da palavra ‘si mesma' (self) (na medida em que tal significa algo como 'pessoa', 'ser humano', 'ele mesmo', 'eu mesmo') ou qualquer análise desse ser, mas o estado de atenção de um filósofo quando ele diz para si a palavra 'self e tenta analisar o seu significado (E muito poderia ser aprendido com isto."
} 
I. De fato, quase sempre a introspecção é um instrumento incontornável de AC e é uma instância de conhecimento direto dos meus estados mentais ou psicológicos. Donde resulta que quase sempre o AC seja AC por introspecção (ACI).

II. AC não é o mesmo que conhecimento acerca da minha pessoa. O meu psicanalista, por exemplo, pode saber muitas coisas acerca da minha psychê, do modo como eventualmente reagirei a esta e àquela situação, etc., coisas que eu não sei de mim mesmo, mas esse conhecimento não é, por natureza, um conhecimento daquilo que designo por AC. Note-se que o conhecimento do meu psicanalista é da terceira pessoa, enquanto o $A C$ é sempre um conhecimento de primeira pessoa.

III. O ACI é dependente da memória (existe um fator tempo estrutural em todo o ACI, característica que é frequentemente esquecida por muitos filósofos. $^{2}$

IV. Se o ACI é dependente da memória, não deixa de ser, por isso, um conhecimento direto (não mediado). Não poderá ser tratado por analogia com o que alguns autores chamam "conhecimento perceptivo deslocado" (por exemplo, sei que a pessoa A esteve nesta sala porque estou vendo o seu chapéu que ela esqueceu).

V. O AC se expressa em retrodicções, isto é, em afirmações acerca dos meus estados mentais passados (não confundir com afirmações acerca da minha pessoa no passado).

VI. O AC que não é ACI não depende da memória. Tipicamente, corresponde linguisticamente a expressões no presente do indicativo, que possuem uma natureza epistêmica diferente. Nomea-

${ }^{2} \mathrm{O}$ problema, a meu ver, é que o ACI dependente da memória preserva a identidade do sujeito porque, mesmo que o entendamos como uma coleção de eu-pensamentos, tal coleção tem de possuir alguma conexão diacrônica. Por exemplo, Elisabeth Anscombe não parece reconhecer esse papel da memória para a conexão dos eupensamentos, mas ao mesmo tempo ela fala de um sujeito destes eu-pensamentos, em que a memória se encontra presente. "Os eu-pensamentos que possuem agora esta conexão com E. A. são eu-pensamentos da parte do mesmo ser humano, enquanto os eu-pensamentos tiveram aquela conexão há vinte anos. Não surge um problema de continuidade ou de re-identificação do 'eu'. Não existe tal coisa. Há a E. A., a qual, como outros seres humanos, tem esses tais pensamentos. Aquela que provavelmente aprendeu a tê-los através da aprendizagem a dizer o que fez, esteve a fazer, etc. - um extraordinário .. de imitação" (Anscombe, 1981, p. 21-37). damente, elas não apenas possuem autoridade própria da primeira pessoa, mas são também infalíveis. Refiro-me a expressões como "estou com fome", "estou furioso", "tenho a intenção de sair da sala", etc., as quais são expressões de estados mentais ou psicológicos, as quais requerem somente condições de sinceridade. No entanto, é possível considerar, se aceitarmos recentes posições no campo da psicologia cognitiva (falaremos desse tópico um pouco mais à frente), que mesmo expressões desse tipo não são totalmente independentes da memória, supondo a existência de uma "working memory" introduzida nos estudos atuais das neurociências e de alguma psicologia cognitiva.

VII. O ACI possui uma estrutura reflexiva apenas no sentido de possuir uma estrutura temporal dual. Não é reflexiva no sentido de apresentar uma dualidade em que um pensamento de segunda ordem toma como alvo ou objeto um pensamento de primeira ordem. Por exemplo, a retrodicção "estive triste ontem" é um ACI que possui uma estrutura temporal dual (agora eu recordo o meu estado de ontem), mas não possui estrutura dual no sentido em que expressa um pensamento (segunda ordem) que tome como alvo outro que tenha ocorrido ontem (primeira ordem) e que eu agora recupero como se tratasse de um objeto independente da memória.

VII. Para tornar ainda mais clara a distinção entre os dois tipos de dualidade, considere-se que a retrodicção (que não é um AC) "A. M. disse ontem que estava triste" é uma afirmação de segunda ordem que toma como alvo ou objeto a minha frase proferida ontem: "estou triste". Na verdade, essa dualidade que encontro nessa afirmação de segunda ordem consiste em ter como alvo um objeto de primeira ordem, ou seja, o fato de eu ter afirmado ontem: "estou triste". Ora uma retrodicção que seja uma peça de ACI, como, por exemplo, "estive triste ontem" não é detentora de uma dualidade daquele tipo.

VIII. O ACI possui, como já se viu, autoridade da primeira pessoa com respeito aos conteúdos da nossa própria mente, ainda que seja falível, porque as retrodicções são dependentes da memória e 
ela introduz, inevitavelmente, falibilidade.

IX. Retrodicções como "estive triste ontem", que possuem autoridade da primeira pessoa, são infalíveis e são exemplos de ACI, o que não é o caso da retrodicção correspondente "estive em Paris na semana passada”, a qual não possui essa autoridade e não é, por consequência, ACI. No entanto, é de sublinhar que ambas as retrodicções são falíveis.

No que se segue, não tratarei de cada ponto em separado; pretendo, por outro lado, identificar algumas linhas de exploração das teses expostas contra o background das perspectivas de alguns autores mais significativos. Comecemos com Fred Dretske, cujo livro Naturalizing the Mind (1995) contém um capítulo inteiro intitulado, precisamente, "Introspection". Uma definição intuitiva dela poderia ser "o conhecimento direto da mente por si mesma” (Dretske, 1995, p. 39), ao que ele acrescenta que a introspecção é um "modo de conhecimento deslocado (displaced knowledge)".

\begin{abstract}
Conhecimento introspectivo é conhecimento da mente - isto é, de fatos mentais. A partir do momento em que os fatos mentais (de acordo com a tese que proponho) são fatos representacionais, o conhecimento introspectivo é uma representação (conceptual) de uma representação - do fato que algo (de diferente) é uma representação ou possui um certo conteúdo representacional. Neste sentido, é metarrepresentacional. Metarrepresentações não são apenas representações de representações. Elas são representações daquelas enquanto representações (Dretske, 1995, p. 43).
\end{abstract}

Em seguida, os exemplos que Dretske dá são analogias com representações de objetos externos: posso ver uma foto como um pedaço de papel, como um objecto com dois gramas, como uma foto de Clyde, etc. Sugiro, no entanto, que essa característica da introspecção como representação dos nossos próprios estados mentais enquanto ou como algo representado parece difícil de aceitar. Usualmente, eu não me represento como triste, mas estou, ou estive simplesmente triste. Casos em que me represento como triste configuram tipicamente situações, em que (seja numa pintura, seja numa fotografia ou na minha imaginação). Mas estas situações não são modos de AC. Claro que uma maior atenção retrospectiva sobre a minha recordação pode levantar-me dúvidas acerca da minha tristeza e então perguntarei a mim mesmo se aquilo que senti terá sido um genuíno sentimento de tristeza, ou qual a razão pela qual estava triste, etc. De qualquer forma, em tais casos seria mais adequado falar de operações contínuas e associadas de memória. Contudo é de sublinhar que esses casos não possuem uma forma dual (a que já me referi), que consistiria numa representação de primeira ordem, que é colocada como representação ou alvo, e uma outra, metarrepresentação da primeira. Mesmo uma retrodicção com alguma complexidade, tal como "Estive triste em Paris por esta e aquela razão [...]", não consiste numa metarrepresentação de representações de primeira ordem. A situação que precisamente simularia uma situação de metarrepresentação seria, por exemplo, ver-me num segundo espelho, que me espelha num primeiro espelho. Porém esse cenário não simula adequadamente um ACI. Neste, aquilo que acontece é um recordar o meu estado mental passado, quando estava triste, e não equivale a qualquer espécie de representação intermédia; é um conhecimento interno (ocorrido num tempo 2), que consiste essencialmente na lembrança de um evento passado (ocorrido num tempo 1). Reconhecendo a dificuldade suscitada pela sua definição de conhecimento introspectivo, Dretske afirma o seguinte:

Pode parecer que esta concepção de conhecimento introspectivo - como uma espécie de percepção deslocada - faz dele uma forma de conhecimento por inferência e, assim, uma forma de conhecimento indireto. Se o conhecimento introspectivo de si mesmo - aquele que representa o mundo desta ou daquela forma - possui a mesma estrutura que possui o conhecimento que o carteiro chegou ao ouvirmos o cão ladrar, então há um 'passo' intermédio no raciocínio que torna indireto o conhecimento do objecto ou alvo. Existem duas maneiras de saber que o carteiro chegou: ou vendo ou ouvindo ele chegar, ou vendo e ouvindo algo diferente (o cão) que nos 'diz' que o carteiro chegou. Se, segundo uma teoria representacional, o conhecimento introspectivo é mais semelhante a este último do que ao primeiro, então a concepção representacional falha em dar ao autoconhecimento (self-knowledge) o caráter imediato que nós sabemos que ele possui (Dretske, 1995, p. 60). 
Em consequência, Dretske acrescenta que essa é uma objeção relevante feita à analogia que ele reivindica entre introspecção e conhecimento perceptivo deslocado, mas insiste que, numa afirmação como "eu represento k como azul”, a qualidade introspectiva advém (e essa é a diferença fundamental, segundo o autor, entre conhecimento deslocado perceptivo e conhecimento deslocado introspectivo) do fato de que, para a verdade da informação da minha representação de "azul”, não é relevante se aquilo que eu vejo ou represento é ou não é azul. O fato relevante, nessa afirmação introspectiva, é o de eu representar k (1995, p. 61). É possível concluir, relativamente à posição de Dretske, que o conhecimento introspectivo é, por um lado, deslocado (como algum conhecimento perceptivo: saber que o carteiro chega pelo ladrar do cão), e, por outro, lado imediato. Porém a compatibilidade dessas duas propriedades, deslocação e ser imediato, não é, a meu ver, convincentemente argumentada.

Somos, a partir daqui, levados a outro ponto da natureza reflexiva da introspecção e do AC. Como Dretske, Tyler Burge e, mais recentemente Pierre Jacob $(2010)^{3}$ aceitam a estrutura reflexiva como básica em todo o AC. Já comentei a perspectiva de Dretske de conhecimento deslocado, assim como o seu desejo de preservar a característica reflexiva da introspecção e as dificuldades que ele acaba por reconhecer. No caso de Burge, é possível encontrar dificuldades no que respeita ao AC como estrutura reflexiva dual, ainda que de outro tipo daquelas que se encontram em Dretske. O caso de Burge é bastante específico, no sentido em que ele considera que, por um lado, ao menos algumas expressões de AC não parecem requerer uma estrutura dual, a partir do momento em que o pensamento-alvo (primeira ordem) coincide em tempo e conteúdo com o pensamento do sujeito (segunda ordem). Mas, por outro lado, o AC envolve

${ }^{3}$ Para uma discussão detalhada do modelo de conhecimento deslocado de Dretske aplicado ao AC, ver P. Jacob (2010, p. 3). O quadro teórico da discussão é determinado pelo desejo de Jacob de mostrar que "a nossa imagem de autoconhecimento introspectivo deriva de duas fontes tradicionais: a epistemologia racionalista e a epistemologia empírica". necessariamente a diferença entre pensamentos de nível de primeira e de segunda ordem, sobre os quais assenta toda a reflexão. Observemos, pois, com algum detalhe, o ponto de vista defendido por Burge relativamente a esse tópico.

Burge vê as diferenças entre o AC e o conhecimento perceptivo no estatuto pessoal (personal status) daquele. Nomeadamente, nos altos de AC, estamos perante afirmações que são realizadas simultaneamente a partir da perspectiva e acerca da primeira pessoa. Ele identifica essa característica nos seguintes termos: "o ponto de vista e o tempo do juízo tem que ser o mesmo do pensamento que é julgado ocorrer" (Burge, 1988, p. 651). E acrescenta que, "quando faço o juízo estou pensando que escrever requer concentração, o tempo do juízo e do pensamento julgado é o mesmo" (1988). Isso significa também, como Burge esclarece noutra passagem do mesmo ensaio, que "o juízo reflexivo herda simplesmente o conteúdo do pensamento de primeira ordem" (p. 650). A diferença essencial, relativa ao conhecimento perceptivo, consiste no status pessoal do AC, ou, em outras palavras, no uso de pronomes da primeira pessoa (eu, meu), pelo que ele observa: "em todos os casos de autoconhecimento autoritário (authoritative self-knowledge), mesmo naqueles casos que não são "básicos" no sentido em que empregamos esse termo, é claro que o seu caráter de primeira pessoa éfundamental para o seu status epistêmico" (p. 651). Assim é a autoridade da primeira pessoa, e não tanto a sua estrutura reflexiva, que confere um status epistêmico especial ao AC, se o compararmos com a percepção. Ou talvez, noutros termos, a interpretação correta da perspectiva de Burge é que é a estrutura do AC, mais a autoridade da primeira pessoa, que lhe confere a sua peculiar natureza epistêmica. No entanto, se aceitarmos a descrição que Burge faz do AC, uma característica dele (o fato de o pensamento que eu tenho possuir o mesmo conteúdo e coincidir, no tempo, com aquilo que é pensado como alvo) não coloca ambos os tipos de conhecimento muito longe um do outro. Afinal, no conhecimento reflexivo (como todo o ACI deve ser), não é possível encon- 
trar mais do que um conteúdo. Isso significa que o pensamento de primeira ordem tomado como alvo (targeted) não possui um conteúdo por si mesmo.

Esseéum aspectonotável para redesenharmos o conceito tradicional de reflexão e de introspecção. É interessante considerar outra característica desse redesenho, se considerarmos que, no AC, cada evento tomado como alvo pode ser visto como um reconhecimento do que acontece ou do que me acontece. Saliente-se, aqui, o ponto de vista de Wittgenstein sobre a natureza da recognição, na medida em que descreve um conjunto de equívocos que surgem inevitavelmente quando a memória opera. Desde logo se confirma uma "fusão" num só conteúdo, tal como nos refere Burge. Encontramos, em Wittgenstein, uma descrição feliz dessa coincidência entre juízo (pensamento), tomado como alvo na memória e ocorrido em 11 e um juízo (pensamento atual) que o sujeito exprime em $\mathrm{t} 2$. Essa descrição é desenvolvida a partir de uma reflexão sobre o uso do processo de "reconhecer algo":

Dos processos a que chamamos 'reconhecer' fazemos facilmente uma imagem errada; como se reconhecer consistisse sempre em comparar duas impressões uma com a outra. É como se eu trouxesse comigo a imagem de um objeto e, a partir dela, identificasse um objeto dado como sendo aquele que a imagem representa. A nossa memória parece nos induzir tal comparação, porque conserva uma imagem do que foi visto anteriormente, ou porque nos permite olhar (como através de um tubo) para o passado (Wittgenstein, IF, p. 604).

Mas, continua Wittgenstein (IF, 605), esse é um entendimento equivocado, porque, na verdade, “[...] não é tanto que eu compare o objeto com uma imagem ao seu lado, mas antes que o objeto coincide com a imagem. Logo, só vejo uma coisa, não duas."

Voltando à argumentação de Burge e assumindo essa coincidência ou fusão entre conteúdos, que faz com que todo o conhecimento ocorrido pela e na memória possua uma estrutura dual temporal (t1 e t2), mas um único conteúdo, devemos, então, nos perguntar o que diferencia o
ACI de outro qualquer conhecimento com aquela estrutura. No fundo, e repetindo o exemplo anterior, o que pode diferenciar um ACI como "estive triste em Paris" de um pensamento do tipo "naquele dia estive na torre Eiffel", no qual não é expresso um AC (que é sempre conhecimento direto dos meus estados mentais), mas um conhecimento gerado na e pela memória? A diferença que desde logo se impõe é a característica incontornável de o AC possuir autoridade de primeira pessoa. No exemplo anterior, a segunda frase não possui, de fato, essa autoridade. Quais as consequências de teor epistêmico que decorrem dessa diferença? Burge introduz a infalibilidade, apenas atribuível a juízos detentores dessa autoridade, mas não concordo que essa seja uma diferença epistêmica fundamental: qualquer ACIé falível, bastando, para tanto, ser dependente da memória. A autoridade da primeira pessoa não implica, pois, infalibilidade no processo de introspecção, o que afeta diretamente qualquer ACI. Convém, no entanto, neste momento, explorar com mais pormenor as semelhanças e diferenças entre os conceitos até aqui utilizados e, em particular, tentar fixar com o maior rigor possível o estatuto do AC, incluindo o ACI. Usando tais critérios, parece difícil manter que o AC é claramente distinto do conhecimento perceptivo, a partir do fato de que, em ambos, existe um conteúdo. No entanto, como já referi, uma diferença importante subsiste: existe estruturalmente, em todo o AC que seja ACI, uma distância temporal entre tempos diferentes, indissociável do trabalho da memória. A retrodicção: "estive há uma semana triste em Paris", a qual exprime um ACI, partilha algumas características importantes com o conhecimento perceptivo, mas esse trabalho da memória, sem o qual não é possível falar em conhecimento, não se encontra presente. Por isso a minha posição diferencia-se da de Burge, não tanto na reivindicação da existência de um único conteúdo, no caso do conhecimento reflexivo ("reflexive judgment simply inherits the content of the first-order thought), com o que concordo. Afastome, isso sim, da sua admissão de que, no AC, opera uma estrutura reflexiva típica com uma composição 
dual, baseada num juízo-representação-pensamento alvo de um juízo-representação-pensamento de segunda ordem. Como tentei mostrar, a operação reflexiva existe em todo o AC em que também opera a introspecção e, por isso, é dependente da memória. ${ }^{4}$ OAC é ACI com uma estrutura dual em que a memória se encontra necessariamente envolvida. Por estrutura dual significo então a consciência de um evento passado em t1, o qual é tomado como alvo por uma representaçãopensamento tipicamente expressa em retrodicções em t2. Essa é exatamente a razão pela qual Burge não vê, no AC básico, uma distância temporal, a qual requer o trabalho da memória. Como já mencionei, ele vê o AC como algo que possui uma estrutura dual clássica mais a autoridade da primeira pessoa, e é somente essa propriedade que confere ao AC uma natureza epistêmica especial. Diria que ele tem em mente algo próximo da infalibilidade. As linhas seguintes ilustram, em minha opinião, essa convicção:

A fonte do nosso direito epistêmico forte, a nossa justificação em relação ao nosso autoconhecimento básico não assenta no fato de nós conhecemos bastantes coisas acerca de cada pensamento que sabemos que temos. Reside, antes, no fato de podermos explicar sua natureza e suas condições de possibilidade. Reside também no fato de nos encontrarmos, ao pensar esses pensamentos, num modo de segunda ordem de autoverificação (Burge, 1988, p. 654).

Porém todo esse entendimento da natureza do AC é problemático para alguns autores contemporâneos relevantes na filosofia da mente e da linguagem. É o caso de Donald Davidson, que afirma:

[...] claro que as pessoas têm crenças, desejos, dúvidas e assim por diante; mas conceder isso não é o mesmo que sugerir que crenças, desejos e dúvidas sejam entidades na ou diante da mente,

${ }^{4}$ Quero insistir que o fato de, no AC, existir um conteúdo não implica que o conteúdo-alvo que ocorreu no passado coincida, no tempo, com a retrodicção que agora exprimo. Precisamente, as retrodicções do AC são sobre eventos passados. O essencial é realmente a consciência de uma distância temporal (ao menos t1 e t2), a qual, por estrita que seja, é sempre preservada. No entanto, se não estou errado, a posição de Burge elimina (ou pelo menos desvaloriza) qualquer distância temporal. ou que nos encontrarmos em tais estados (mentais) exija que haja objetos mentais correspondentes (Davidson, 2001, p. 35-36).

Assim, se não existem estados mentais como objetos na mente, os quais se poderiam captar num determinado sentido, não existe, por consequência, aos olhos de Davidson, algo como a introspecção, num sentido usual. Todavia o seu ponto fundamental é que não é necessário que esses estados ou objetos existam de forma a exprimirmos uma atitude (proposicional). Nas suas palavras,

[...]ter uma atitude não é o mesmo que ter uma entidade diante da mente; por razões compulsórias de ordem psicológica e epistêmica, devemos negar a existência de objetos da mente (Davidson, 2001, p. 36).

Acredito que Davidson tenha razão nessa formulação, no entanto sugiro que deveríamos ir mais longe no esclarecimento do que sejam essas "razões compulsórias de ordem psicológica e epistêmica". É nesse ponto que o problema que tenho colocado acerca da natureza do AC pode ser formulado nos seguintes termos: afigura-se contraintuitivo negar simplesmente a existência de introspecção e do correspondente AC, mas não também não é necessário, como já argumentei, que devamos assumir a existência, na mente, de estruturas reflexivas duais, de pensamentos ou representações que funcionem como objetos-alvo (exatamente como acontecerá com qualquer objeto empírico) e toda a espécie de objetos que qualifiquem oconhecimentointrospectivo comotal.Éprecisamente aqui que se torna inevitável a introdução do fator tempo ou, por outras palavras, da memória: a retrodicção acerca do meu próprio estado mental ou psicológico feita em t2 sempre se refere ao acontecimento t1. Em consequência, devemos aceitar a existência de uma estrutura dual, mas trata-se de uma dualidade de presente e passado, e não de uma dualidade reflexiva geralmente apontada pela epistemologia clássica, a qual, no fundo, tem sempre de assumir objetos na mente prontos a serem apreendidos por um ato mental novo, como se se tratasse de um conhecimento perceptivo. Se se 
aceitar usar o termo “reflexão”, é como operação mental realizada com a estrutura dual que envolve a memória que se "dirige" a um tempo passado.

Existirá, pois, sempre uma estrutura temporal dual num ACI, que requer, repito, pelo menos duas coisas: 1) ser direto, ou seja, não mediado como qualquer outro conhecimento deslocado, no sentido referido atrás e 2) possuir autoridade da primeira pessoa. Essas são qualidades do AC que tanto Dretske como Burge aceitam, mas não associadas a envolvimento determinante da memória. Estudos recentes sobre a memória e, especialmente, sobre $a$ memória de curta duração, mas também sobre aquilo que distingue essa espécie de memória da memória de longa duração, também nos permitem entender o papel que a memoria de curto termo desempenha, mesmo no caso em que representações ou pensamentos coincidem (no tempo) com os correspondentes conteúdos. Os psicólogos chamam a essa memoria de curto prazo de "working memory" e ela pode ser definida nos seguintes termos:

A 'working memory' pode ser entendida como um reservatório de baixa capacidade informativa que se encontra sempre cheio e para onde as sensações constantemente fluem, sendo da mesma forma esquecidas [...]. A 'working memory' é uma forma indispensável de memória de transição; é uma janela móvel de compreensão que nos permite entender o presente nos termos do passado muito recente (O’Shea, 2005, p. 85).

É o que se passa sempre que a forma gramatical é equivalente a declarações no presente do indicativo. Basta pensar em afirmações como "estou a compreender este texto", "digo-te que estou feliz", "estou vendo este pôr do sol como um quadro de Rothko", etc. Essas são afirmações que parecem não ter a mesma estrutura de simples expressões no sentido da palavra inglesa avowals. Precisamente elas envolvem uma working memory que possibilita operações cognitiva e estão presentes em toda a aprendizagem da língua. ${ }^{5}$

A forma de conceber o ACI conduz-nos ao problema do estatuto do conteúdo das retrodicções

5 Para muitos psicolinguistas, a working memory está implicada na compreensão sintática ou na retenção do trajeto de dependência sintática . Para além disso, a working memory torna possível operações cognitivas, que são dependentes da memoria e são diferentes das retrodicções que não o são. A retrodicção "estive em Paris na semana passada” é precisamente desse tipo, e não é um exemplo de introspecção, mesmo que possua a estrutura dual temporal. No entanto, como já argumentei, não dispõe de autoridade da primeira pessoa. Efetivamente, o conteúdo dessa retrodicção pode ser confirmado por outra pessoa que me tenha visto em Paris. Assim, o conteúdo, "o fato de A. M. ter estado em Paris na semana passada” não possui a autoridade da primeira pessoa. $^{6}$

A minha tristeza passada nãoé definitivamente oalvo de uma metarrepresentação, mas simplesmente o conteúdo de um pensamento ou representação que, nesse caso, é uma recordação de um estado mental ou psicológico ou de uma vivência. O que acontece é, antes, o seguinte: o assim designado conteúdo de primeira ordem, isto é, o fato de eu me encontrar triste num tempo t1 é recordado num tempo, t2. Será que a representação em t2 é uma metarrepresentação do que ocorre em $\mathrm{t} 1$ ? Diria que não é, e posso ilustrar essa asserção com a seguinte observação, retirada das Investigações Filosóficas de Wittgenstein: “Tem sentido fazer-se a pergunta: 'Como sabes que acreditas' e constitui uma resposta: ‘Reconheço-o por introspecção’? Em alguns casos, poder-se-á dar essa resposta, geralmente não. Tem sentido perguntar "É amor o que realmente sinto por ela, ou estou apenas a enganar-me a mim

tais como a atenção centrada em objetos-alvo, numa ocorrência temporal. Por exemplo, o juízo, “agora estou a comprender este argumento" envolve working memory e até elementos explícitos no passado que possibilitam a compreensão e estão, por assim dizer, linguisticamente escondidos. Confronte C. Philip Beamen, "Working Memory: Beyond Language and Symbolism”, Current Anthropology, v.51, June, 2010. p. S27-S38, and Conway, A.R-A, M. Kane, M. Bunting, Hambrick, O. Wilhelm, and R.W. Engle, 2005, "Working memory span tasks: a methodological review and user's guide", Psychonomic Bulletin and Review, v.12, p. 796-786, 2005.

${ }^{6}$ A autoridade da primeira pessoa em simples afirmações ou retrodicções deve preencher a seguinte condição: a total assimetria no respeitante às condições de verdade do conteúdo da frase correspondente na terceira pessoa. Assim "eu (A.M.) estive em Paris na semana passada" possui a mesma condição de verdade de "Ele (A.M.) esteve em Paris na semana passada." Não são afirmações assimétricas. Porém é claro que a afirmação "Eu (A.M.) estive triste em Paris na semana passada", a qual possui autoridade da primeira pessoa, é assimétrica em relação a quaisquer condições de satisfação da correspondente frase proferida na terceira pessoa. 
próprio?”e aqui o processo de introspecção consiste em tornar as recordações vivas; reencontrar imagens de situações possíveis e das sensações que se teriam se [...]” (IF, 587).

O que é notável nessa observação de Wittgenstein é que, para ele, a introspecção, por assim dizer, alcança o seu alvo na maioria dos casos por uma operação de recordação, de memória. Por outras palavras, na maioria dos caos, a estrutura de introspecção requer um fator tempo e, sem isso, não existe qualquer alvo. (No exemplo desta observação, o alvo ou objeto é a qualidade de um sentimento). Por outro lado, quando a memória não desempenha um papel, parece que Wittgenstein recusa a introspecção. Sem memória, não existe alvo, não existe introspecção. Possivelmente, os casos em que Wittgenstein diria que não faz sentido falar de introspecção são do tipo: acreditar que $p$, observando a minha crença, parece absurdo ou impossível. Note-se que, mesmo algumas afirmações, como "agora acredito que $p$ ", implicam que, eventualmente, não acreditei no passado que $p$. Porém esse contraste apenas necessita que tomemos consciência do fator tempo. Na verdade, o que é mais plausível, tendo em conta a observação acima citada, é que Wittgenstein considere que, nalguns casos, em que o tempo não intervém, não faz sentido falar em introspecção. Será que o questionamento dependente da memória é verdadeiramente AC (como quando reencontro "imagens de situações possíveis e das sensações que se teriam se [...]”)? Será que existem outras formas de AC que excluam a memória e, por isso mesmo, são pseudo AC? Wittgenstein não o explicita, mas é razoável pensar que é o que ele quer significar.

Como uma conclusão não definitiva, defendo que o ACI possui pelo menos três características: ter uma estrutura temporal dual baseada na memoria, ser direto e possuir autoridade da primeira pessoa.

Recebido para publicação em 19 de outubro de 2012 Aceito em 04 de novembro de 2012

\section{REFERÊNCIAS}

ANSCOMBE, E. The First Person, Metaphysics and the philosophy of mind: collected philosophical papers, v.2. Oxford: Blackwell, 1981.

BURGE, Tyler. Individualism and self-knowledge. Journal of Philosophy, v.85, n.11, p.649-663, 1988.

Press, 2007

Foundations of the mind. Oxford: Clarendon

DAVIDSON, Donald. Subjective, intersubjective, objective, Oxford: Clarendon Press, 2001. (Chapter: "Knowing One's Own Mind")

DRETSKE, Fred. Naturalizing the mind. Cambridge, Mass.: MIT Press, 1995.

HUME, David. A treatise of human nature. London: Penguin, 1984.

JACOB, Pierre. Do we know how we know our own minds yet? 2010. Disponível em: http://jeannicod.ccsd.cnrs.fr/ docs/00/05/34/50/HTML/index.html

KANT, Immanuel. Critique of pure reason. Trans. N. Kemp Smith. London: Macmillan, 1992.

LOCKE, John. Essay concerning human understanding. [S.l.,s.n.]1690.

O'SHEA, Michael . The Brain. Oxford: Oxford University Press, 2005.

STRAWSON, Galen. Selves, Oxford: OUP, 2009.

WITTGENSTEIN, Ludwig, Investigações Filosóficas, Lisboa: Fundação Gulbenkian, 1995.

(Citações das Investigações Filosóficas (IF) são feitas segundo a forma usual, apenas com referência ao número da secção). 


\section{SELF-KNOWLEDGE, INTROSPECTION AND MEMORY}

\author{
António Marques
}

The paper addresses the operative place of memory in self-knowledge. Making use of classic references, particularly those stemming from the dispute between empiricism and rationalism, it aims to show that knowledge of the own self, which is only attainable by introspection, is relatively poor. Opposing dual structures of presentation of the problem, the paper suggests that the clarification of what can be considered self-knowledge and introspection requires the consideration of the role played by memory and the evaluation of the epistemic nature of postdictions (i.e., statements about past events - in this case, about mental past events). By way of non-definitive conclusion, distinguishing self-knowledge from self-knowledge by introspection, the paper claims that self-knowledge by introspection has at least three characteristics: it has a dual temporal structure based on memory, it is direct, and it has first-person authority.

KEY-WORDS: Self-knowledge. Memory. Skepticism. Introspection.

\section{CONNAISSANCE DE SOI, INTROPESCTION ET MÉMOIRE}

\author{
António Marques
}

Létude se penche sur le lieu opératif de la mémoire dans la connaissance de soi. Nous nous servons des références classiques et tout particulièrement de celles provenant de la confrontation entre empirisme et rationalisme par introspection. L'intention est de montrer que la connaissance de soi-même, qui ne peut être acquise que par introspection, est relativement pauvre. En opposition aux structures duales de présentation du problème, il est suggéré dans ce texte que pour clarifier ce qui peut être considéré comme connaissance de soi et introspection exige de prendre en considération le rôle joué par la mémoire et par l'évaluation de la nature épistémique des rétrodictions (c'est-à-dire des déclarations concernant des événements passés, dans le cas présent, d'événements mentaux passés). En guise de conclusion qui n'est d'ailleurs pas définitive, et faisant la distinction entre connaissance de soi et connaissance de soi par introspection, notre texte affirme que la connaissance de soi par introspection est dotée au moins de trois caractéristiques : avoir une structure temporelle duale basée sur la mémoire, être direct et posséder l'autorité de la première personne.

Mots-CLÉs: Connaissance de soi. Mémoire. Scepticisme. Introspection

António Marques - Doutor em Filosofia. Professor e Diretor do Instituto de Filosofia da Linguagem. Faculdade de Ciências Sociais e Humanas da Universidade Nova de Lisboa. Foi bolsista da Fundação Humboldt, e pesquisador visitante a convite da Universidade de Boston. Publicou diversas contribuições dedicadas a, entre outros, Kant, Nietzsche e Wittgenstein, tendo também traduzido obras fundamentais como a Crítica da Faculdade do Juízo de Kant e os Últimos Escritos sobre a filosofia da psicologia de Wittgenstein. Em torno ao comentário sistemático deste último integra a coordenação do Grupo Luso-Brasileiro de Estudos Wittgensteinianos, apoiado pela Universidade Nova de Lisboa (através do IFL), a Unicamp e a UFBA. Publicações recentes: A Razão Judicativa, Imprensa Nacional/Casa da Moeda, 2004; O Interior - Linguagem e Mente em Wittgenstein, Fund. Calouste Gulbenkian, 2003. 